\title{
Sub Parts-Per-Million Mass Measurement Accuracy of Intact Proteins and Product Ions Achieved Using a Dual Electrospray Ionization Quadrupole Fourier Transform Ion Cyclotron Resonance Mass Spectrometer
}

\author{
D. Keith Williams, Jr., Adam M. Hawkridge, and David C. Muddiman \\ W. M. Keck FT-ICR Mass Spectrometry Laboratory, Department of Chemistry, North Carolina State \\ University Raleigh, North Carolina, USA
}

\begin{abstract}
High mass measurement accuracy (MMA) is demonstrated for intact proteins and subsequent collision-induced dissociation product ions using internal calibration. Internal calibration was accomplished using a dual electrospray ionization source coupled with a hybrid quadrupole Fourier transform ion cyclotron resonance (Q-FT-ICR) mass spectrometer. Initially, analyte ions generated via the first electrospray (ESI) emitter are isolated and dissociated in the external quadrupole. This event is followed by a simultaneous switch to the calibrant ion ESI emitter and a disablement of the isolation and activation of the external quadrupole such that a broad $\mathrm{m} / \mathrm{z}$ range of calibrant ions are accumulated before injecting the analyte/calibrant ion mixture into the ICR cell. Two different internal calibrant solutions were utilized in these studies to evaluate this approach for the top-down characterization of melittin and ubiquitin. While external calibration of protein fragments resulted in absolute MMA greater than $16 \mathrm{ppm}$, internal standardization significantly improved upon the MMA of both the intact proteins and their products ions which ranged from $-2.0 \mathrm{ppm}$ to $1.1 \mathrm{ppm}$, with an average of $-0.9 \mathrm{ppm}$. This method requires limited modification to ESI-FT-ICR mass spectrometers and is applicable for both positive and negative ionization modes. (J Am Soc Mass Spectrom 2007, 18, 1-7) () 2007 American Society for Mass Spectrometry
\end{abstract}

$\mathrm{H}$ ybrid quadrupole Fourier transform ion cyclotron resonance (Q-FT-ICR) mass spectrometers [1-5] are uniquely suited for making top-down [6-10]proteomics measurements. The combination of high resolving power (RP) and mass measurement accuracy (MMA) enables the confident determination of both the intact protein mass and the masses of its corresponding dissociation product ions. The combination of these experimental datasets provides confident and unambiguous identification of proteins. To realize the highest achievable MMA for a given FT-ICR mass spectrometer system, frequency shifts due to spacecharge-effects must be accounted for via external or internal calibration methods [11, 12].

External calibration has been used to account for frequency shifts and thereby improve the MMA of intact peptides and proteins [13]. For example, Amster and coworkers developed a calibration curve to account

Published online September 18, 2006

Address reprint requests to Dr. D. C. Muddiman, W. M. Keck FT-ICR Mass Spectrometry Laboratory, Department of Chemistry, North Carolina State University, Raleigh, NC 27695, USA.E-mail: david_muddiman@ncsu.edu for the difference between the ion populations of the calibration spectrum and spectra that were to be externally calibrated resulting in $<10$ parts-per-million MMA [14, 15]. Hunt and coworkers have demonstrated the effectiveness of combining external calibration with automatic gain control (AGC) where the number of ions in the ICR cell were precisely controlled to fall within the external calibration range [5]. This approach allowed them to achieve $<2$ ppm MMA. Muddiman and coworkers were able to achieve $<1$ ppm using this approach [16]. Based partly on the work of Amster [14, 15] and Smith [17], Oberg and Muddiman reported a novel external calibration law which afforded $<5$ ppm MMA [18].

Internal calibration has also been effective at providing high MMA for intact species. However, it can be difficult to implement in the context of modern proteomics experiments, where introducing the calibrant ions concurrently with the analyte species can be problematic (e.g., ion suppression). One approach to internal calibration was reported by Smith and coworkers who developed an algorithm called deconvolution of Coulombic affected linearity (DeCAL) 
[19]. Unfortunately, this approach required multiple charge states for the same species, which are not always present. Muddiman and coworkers have developed and utilized a dual-electrospray emitter (dualESI) to achieve high MMA [20-22]. This approach is amenable to both direct infusion [23-25] and liquid chromatography experiments [26-28] without introducing measurement biases associated with ion suppression. Furthermore, this method does not compromise dynamic range by limiting the number of ions in the ICR cell (e.g., AGC). Despite the prevalence of multiple external and internal methods for calibrating FT-ICR data, AGC $[5,16]$ or internal calibration have thus far been the methods of choice for achieving high MMA for intact species [19-22].

The interpretation and confident assignment of intact proteins and their product ions is a major challenge in top-down proteomics. Robust methods for providing high MMA of intact and dissociated proteins are sorely needed for top-down proteomics to mature into a viable alternative to bottom-up proteomics [29]. A sampling of the current top-down proteomics literature clearly demonstrates the need to address this critical issue in top-down proteomics. To date, reported MMA of product ions range from $-41 \mathrm{ppm}$ to $10 \mathrm{ppm}$, all of which employed external calibration methods $[30,31]$. In some cases the MMA is not reported for the product ions in a tandem-MS experiment [32-34]. Very little research thus far has focused on the development of strategies employing internal calibration as a means for achieving high MMA of top-down proteomics data.

DeCAL was recently applied to tandem-MS data, which resulted in product ion MMAs of $1.59 \mathrm{ppm}$; however, it still required the presence of at least two charge-states for one species [35]. Kelleher and coworkers used "unmodified $\mathrm{z}$ ions" for internal calibration; however, the MMA reported had a range from $0.1 \mathrm{ppm}$ to $44 \mathrm{ppm}$ [36]. Furthermore, this method requires the identity of the protein to generate the exact mass of unmodified $\mathrm{z}$ ions which are used as the internal calibrants [36]. Several years ago, we developed and utilized a dual electrospray source to internally calibrate SORI-CID tandem mass spectrometry data of short oligonucleotides and achieved $<3.2$ ppm MMA on a 7 tesla FT-ICR MS [22].

Herein, we report the internal calibration of intact proteins and their product ions formed by collisioninduced dissociation in a dual electrospray ionization [20-22] hybrid quadrupole FT-ICR-MS using a modified pulse sequence. Internal standards of polypropylene glycol (PPG) and a mixture of four iodopeptides, which fall in an $m / z$ range that is unoccupied by natural (i.e., not chemically modified) peptide/proteins, were chosen for these MS/MS studies. This $\mathrm{m} / \mathrm{z}$ range is also known as the forbidden zone and results from the mass excess of the chemical constituents [24]. This paper presents the capability of a dual ESI source coupled with a QFT-ICR MS to achieve sub-ppm MMA, which will have significant impact for top-down proteomic applications.

\section{Experimental}

\section{Materials}

The PPG with an average molecular weight of $1000 \mathrm{Da}$, melittin, ubiquitin, ammonium acetate ( $>99 . \%)$, and formic acid were purchased from Sigma (St. Louis, MO). HPLC grade acetonitrile and high purity water were purchased from Burdick Jackson (Muskegon, MI). 2-propanol (HPLC Grade) was purchased from Fischer Scientific (Fair Lawn, NJ). The iodopeptides used were synthesized in the Mayo Proteomics Research Center (Rochester, $\mathrm{MN})$. These four iodopeptides had the sequences $\left(\mathrm{I}_{2} \mathrm{Y}\right) \mathrm{GK}$ $\left(\mathbf{I}_{1}\right),\left(\mathrm{I}_{2} \mathrm{Y}\right) \mathrm{GK}\left(\mathrm{I}_{2} \mathrm{Y}\right) \mathrm{G}\left(\mathrm{I}_{2}\right),\left(\mathrm{I}_{2} \mathrm{Y}\right) \mathrm{SR}\left(\mathrm{I}_{2} \mathrm{Y}\right) \mathrm{GSYGSSI}\left(\mathrm{I}_{3}\right)$, and $\left(\mathrm{I}_{2} \mathrm{Y}\right)$ SR $\left(\mathrm{I}_{2} \mathrm{Y}\right)$ GSYGSSIGSY $\left(\mathrm{I}_{4}\right)$ with neutral monoisotopic masses of 617.9836, 1089.8617, 1742.1433, and 2049.2601 $\mathrm{Da}$, respectively. All materials were used as received.

\section{Dual Electrospray Ionization Hybrid Quadrupole Fourier Transform Ion Cyclotron Resonance Mass Spectrometry (dualESI-QFT-ICR MS)}

A modified version of a dual ESI source developed previously in this laboratory [21] was coupled to a hybrid Ionspec (Lake Forest, CA) QFT-ICR mass spectrometer equipped with an actively shielded 7T superconducting magnet (Cyromagnetics, Oak Ridge, TN) and a Z-spray ESI source (Waters Corp, Milford, MA). All spectra were acquired with $1024 \mathrm{k}$ points and an ADC rate of $1 \mathrm{MHz}$. Samples were introduced by direct infusion using a $100 \mu \mathrm{l}$ gas-tight syringe (Hamilton, Las Vegas, NV) and a Harvard Apparatus model PHD 2000 syringe pump (Holliston, MA) at a flow rate of 0.5 $\mu \mathrm{l} / \mathrm{min}$ to $1.00 \mu \mathrm{L} / \mathrm{min}$. The ESI emitter tips used were $360 \mu \mathrm{m}$ o.d., $50 \mu \mathrm{m}$ i.d. and tapered to $30 \pm 1.0 \mu \mathrm{m}$ i.d. (New Objective, Woburn, MA), and held at a constant potential of $2200 \mathrm{~V}$ for all experiments. Electrospray solutions were composed of 1:1 (vol:vol) acetonitrile/ water, with $0.1 \%$ formic acid, with the exception of the ammonium-adducted polypropylene glycol solution, which was composed of 70:30 2-propanol:water with $0.5 \mathrm{mM}$ ammonium acetate $\left(\mathrm{NH}_{4} \mathrm{OAc}\right)$. The generic experimental pulse sequence used for all experiments is shown in Figure 1 (see figure caption).

\section{Results and Discussion}

The primary sequence of melittin with notation of the doubly charged y-ions that we observed is shown at the top of Figure 2. To evaluate the stability of the dualESIQFT-ICR mass spectrometer experimental pulse sequence, 50 sequential internally calibrated collision induced dissociation (CID) mass spectra were collected for two different internal calibrant mixtures. Both ammonium-adducted polypropylene glycol $\left(\mathrm{NH}_{4}\right.$-PPG1000) and a mixture of four iodopeptides were used as 


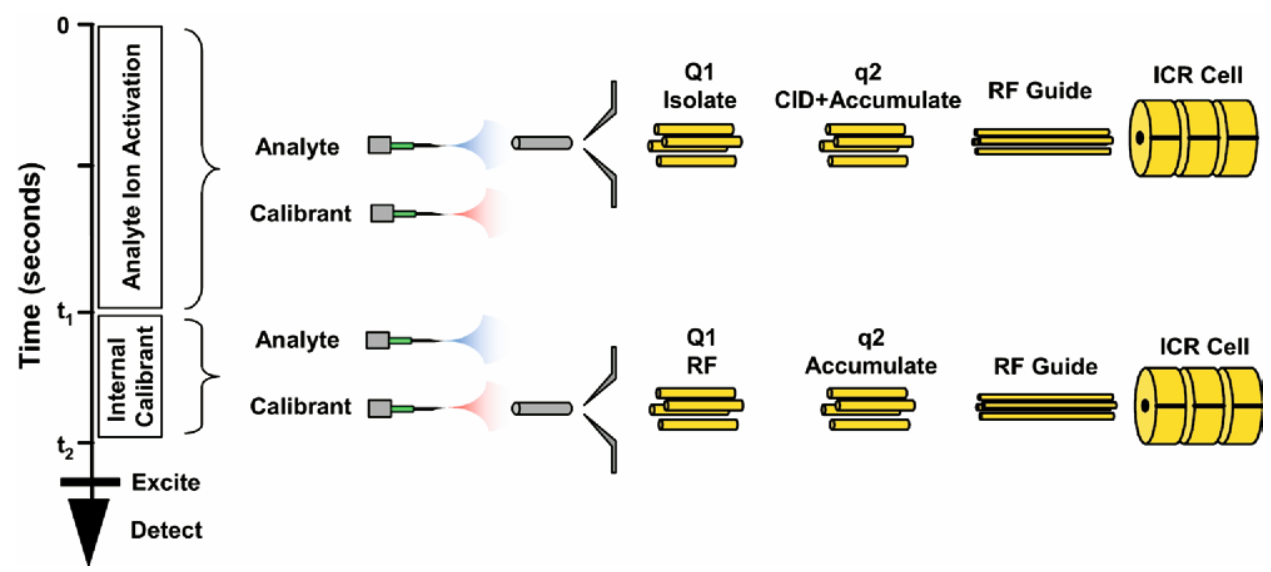

Figure 1. QFT-ICR MS/MS schematic with experimental pulse sequence. The left axis shows the experimental timeline for a single internally calibrated dualESI-QFT-ICR MS/MS acquisition. From $t=0$ to $t_{1}$ the analyte ions are isolated (Q1), dissociated (q2), and accumulated (q2). From $t_{1}$ to $t_{2}$ the emitter position switches to the internal calibrant species, Q1 is reset to broad-band $m / z$ transmission, and the offset voltages for $\mathrm{q} 2$ are reset for accumulation only (i.e., no CID). At $t_{2}$, the analyte/internal calibrant ions are transferred to the ICR cell where they undergo excitation and detection.

internal calibrants. Figure 2a shows a representative "NH 4 -PPG-1000" internally calibrated CID mass spectrum of mellitin labeled as "Spectrum \#2". The " $\mathrm{NH}_{4}^{-}$ PPG-1000" ions were labeled as $12_{\mathrm{A}}, 13_{\mathrm{A}}, 14_{\mathrm{A}} \ldots 20_{\mathrm{A}}$ representing the number of propylene-glycol repeat units. The corresponding total ion abundance plot of the 50 sequential measurements is shown in Figure 2b with the arrows indicating every fifth spectrum. The arrow labeled "Spectrum \#2" indicates the data plotted in Figure 2a.

Figure 2c shows a representative "iodopeptide" internally calibrated CID mass spectrum of mellitin labeled also as "Spectrum \#2". The "iodopeptide" ions were labeled as $\mathrm{I}_{1}, \mathrm{I}_{2}, \mathrm{I}_{3}$, and $\mathrm{I}_{4}$ (see the Experimental section for sequences). The corresponding total ion abundance plot of the 50 sequential measurements is shown in Figure 2d with the location of "Spectrum \#2". In both spectra presented in this figure, the $\mathrm{y}_{13}$-ion is dominant, which is attributed to the presence of a proline (position 14 from the N-terminus) in the melittin sequence [37]. The data presented in Figure $2 b$ and $d$ demonstrate the stability of the pulse sequence albeit the iodopeptide is more variable that we attribute to the ESI emitter.

The $4+$ charge-state of the monoisotopic peak of melittin was observed to have a MMA ranging from $-4.1 \mathrm{ppm}$ to $-1.85 \mathrm{ppm}$ and $-0.17 \mathrm{ppm}$ to $-0.31 \mathrm{ppm}$, respectively, for externally and internally calibrated data using $\mathrm{NH}_{4}-\mathrm{PPG}-1000$. Similarly, when the iodopeptides were used as internal calibrants, the MMA ranged from $-4.23 \mathrm{ppm}$ to $-1.71 \mathrm{ppm}$ and $-0.17 \mathrm{ppm}$ to $-0.31 \mathrm{ppm}$, respectively, for externally and internally calibrated data.

Figure 3 presents the MMA data obtained from the tandem mass spectra of melittin shown in Figure 2. Figure 3a shows the relationship between MMA and the mass-to-charge ratio for external calibrated tandem-MS data using $\mathrm{NH}_{4}$-PPG-1000 (left) and iodopeptides (right) as calibrants. The MMA systematically improves with decreasing mass-to-charge ratio as expected, given the inverse relationship between cyclotron frequency and $\mathrm{m} / \mathrm{z}$ [38].

Similarly, Figure $3 \mathrm{~b}$ shows the internally calibrated data using $\mathrm{NH}_{4}$-PPG-1000 (left) and iodopeptides (right) as internal calibrants. Importantly, the MMA is now centered about $0 \mathrm{ppm}$ and there was no significant correlation between MMA and $m / z$, indicating the systematic error had been removed. The data in Figure 3a and $b$ suggest that $\mathrm{NH}_{4}$-PPG-1000 is a better internal calibrant than the iodopeptides. We attribute this to the fact that there are ten calibrant points for the $\mathrm{NH}_{4}$-PPG1000 opposed to only four for the iodopeptides; however, it could partly be their frequency range relative to the product ions [18].

Figure $3 \mathrm{c}$ shows the cumulative percentage plots as a function of MMA obtained for the externally (red) and internally calibrated (blue) data using $\mathrm{NH}_{4}{ }^{-}$ PPG-1000 (left) and four iodopeptides (right) as the calibrants. The dashed line in Figure $3 \mathrm{c}$ should theoretically intersect the curves shown at $50 \%$ if the MMA was exactly centered at $0 \mathrm{ppm}$. External calibration using either $\mathrm{NH}_{4}$-PPG-1000 or the iodopeptides intersects this dashed line when $100 \%$ of the ions have already been accounted for, clearly demonstrated the presence of systematic error. Internal calibration using either $\mathrm{NH}_{4}$-PPG-1000 or the iodopeptides are approximately centered about $0 \mathrm{ppm}$ MMA, supporting our hypothesis that internally calibrated data would accurately remove the systematic bias. Furthermore, for internally calibrated data using the $\mathrm{NH}_{4}$-PPG-1000 or the iodopeptides, the MMA ranged from $-0.62 \mathrm{ppm}$ to $0.64 \mathrm{ppm}$ and $-1.08 \mathrm{ppm}$ to $1.09 \mathrm{ppm}$, respectively.

Figure 4 shows the primary sequence for ubiquitin 


\section{G I G A V L K KV LL LT IT IG LL IP IA LL II IS W I K R K R Q Q $\mathrm{y}_{19} \mathrm{y}_{18} \mathrm{y}_{17} \mathrm{y}_{16} \mathrm{y}_{15} \mathrm{y}_{14} \mathrm{y}_{13} \mathrm{y}_{12} \mathrm{y}_{11} \mathrm{y}_{10} \mathrm{y}_{9} \quad$ Sequence Coverage $=42 \%$}

(a)
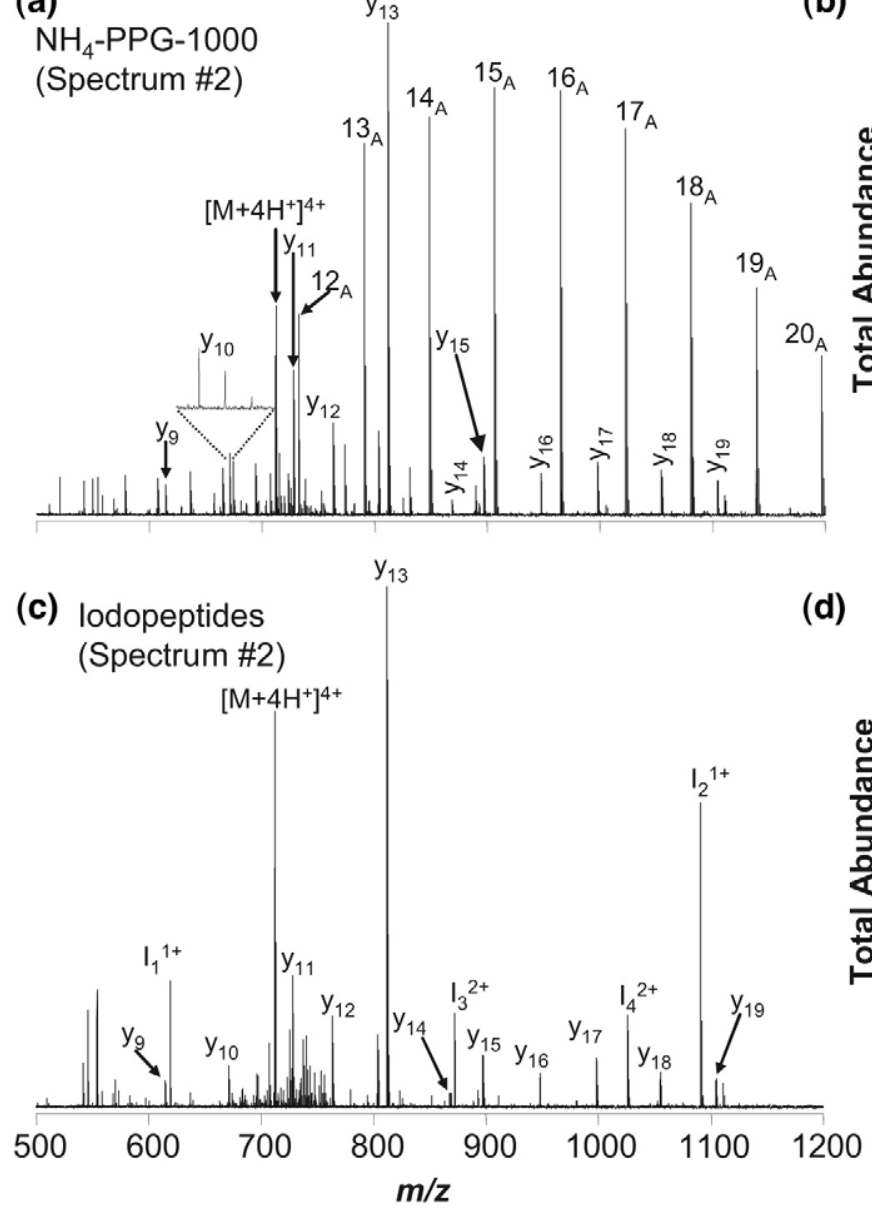

(b)

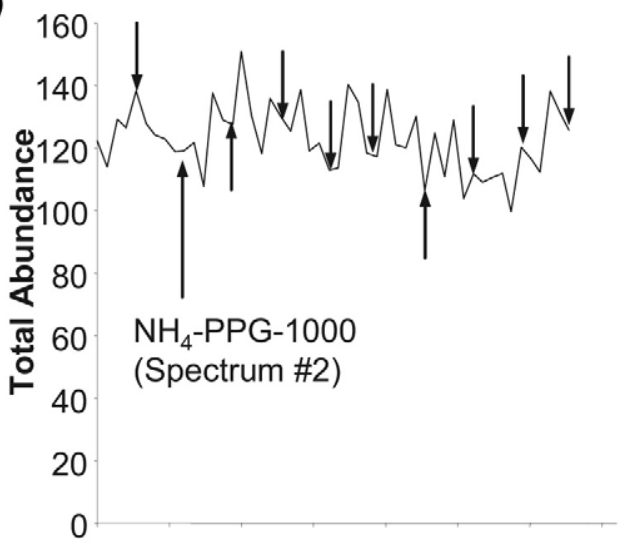

(d)

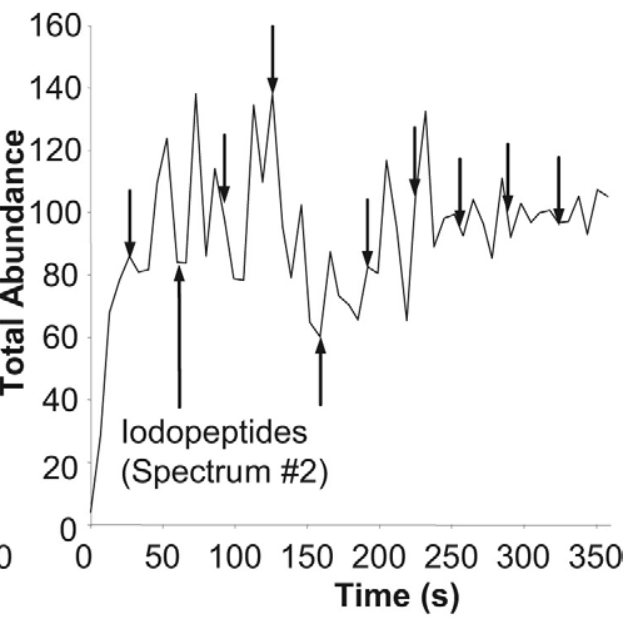

Figure 2. Primary sequence of melittin with observed y-ions. (a) Internally calibrated dual ESI QFT-ICR tandem mass spectra of the $4+$ charge-state of melittin using $\mathrm{NH}_{4}$-PPG-1000, (b) total ion abundance plot of 50 sequential internally calibrated dual ESI QFT-ICR tandem mass spectra of the $4+$ charge-state of melittin using $\mathrm{NH}_{4}-\mathrm{PPG}-1000$, (c) internally calibrated dual ESI QFT-ICR tandem mass spectra of the $4+$ charge-state of melittin using iodopeptides as the internal standards, and (d) total ion abundance plot of 50 sequential internally calibrated dual ESI QFT-ICR tandem mass spectra of the $4+$ charge-state of melittin using four iodopeptides as the internal calibrants.

(top) along with the seven different y-ions observed ( $\sim 9 \%$ sequence coverage). In these studies involving ubiquitin, we only carried out external and internal calibration using the iodopeptide mixture to minimize interference in terms of complexity as well as the ability to access forbidden zones [24]. The single-acquisition QFT-ICR tandem mass spectrum is shown with the y-ions and internal calibrants labeled. The two insets show the expansion of two product ions $\left(\mathrm{y}_{58}\right.$ and $\left.\mathrm{y}_{40}\right)$. The dominant $\mathrm{y}_{58}$ and $\mathrm{y}_{40}$ product ions are attributed to the presence of two prolines (at positions 19 and 37 from the N-terminus), which may provide valuable bioinformatic constraints for top-down proteomic data [37].

The MMA achieved for the externally and internally calibrated data ranged from -16 to $-4 \mathrm{ppm}$ and from -2 to $1 \mathrm{ppm}$, respectively, with the exception of one peak that had a very low abundance. All MMA measurements were calculated from the monoisotopic peak for each of the isotope clusters being investigated. The MMA as a function of $\mathrm{m} / \mathrm{z}$ for the externally (bottom left) and internally (bottom right) calibrated data is shown, once again demonstrating that the systematic error has been removed using internally calibration. The cumulative percentage plot as a function of MMA is also shown for the externally (red) and internally (blue) calibrated data again demonstrating that high MMA can routinely be achieved.

\section{Conclusions}

The utilization of a dual electrospray source coupled to a QFT-ICR MS instrument enabled the generation 
PPG (10 point calibration)
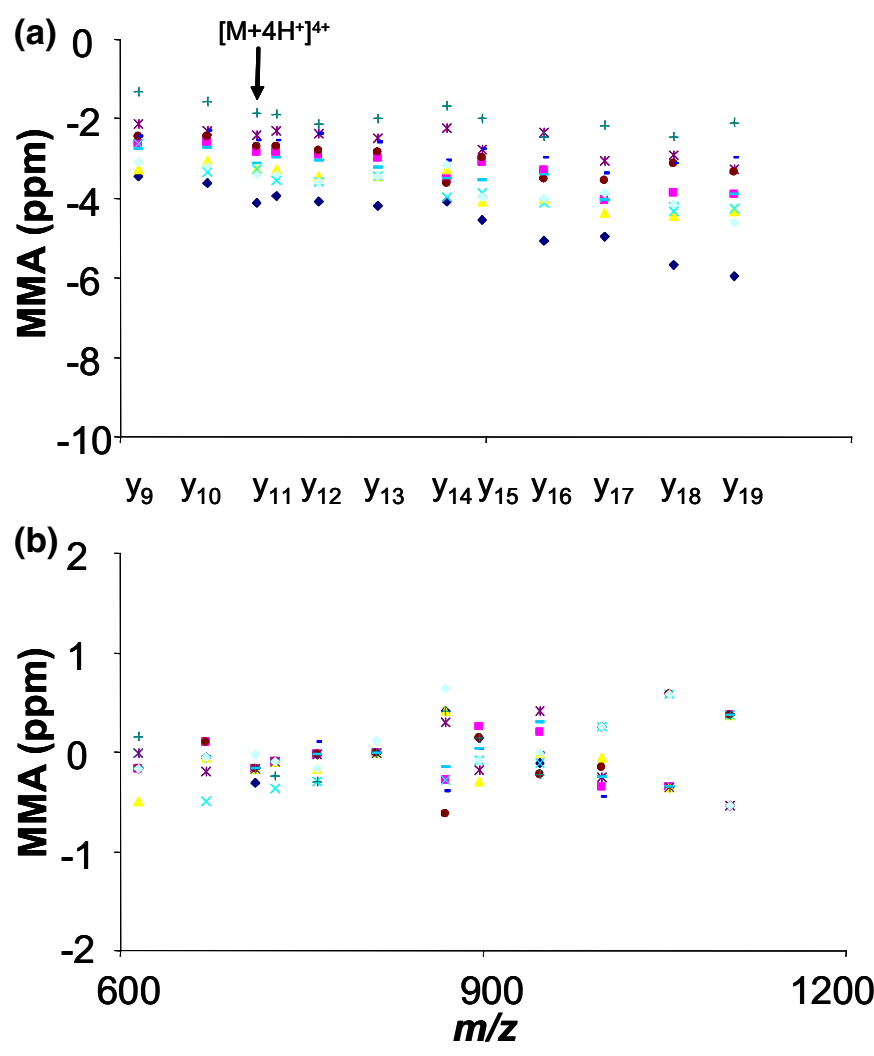

(c)

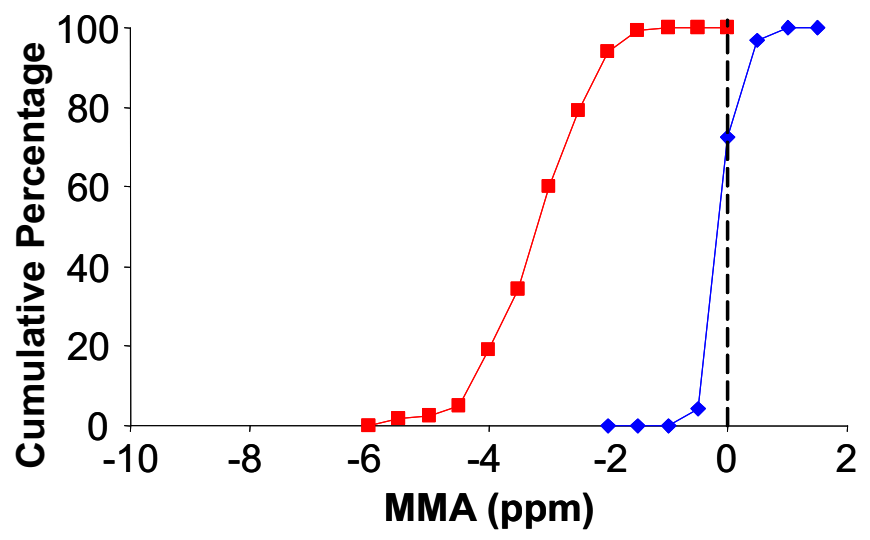

lodopeptides (4 point calibration)

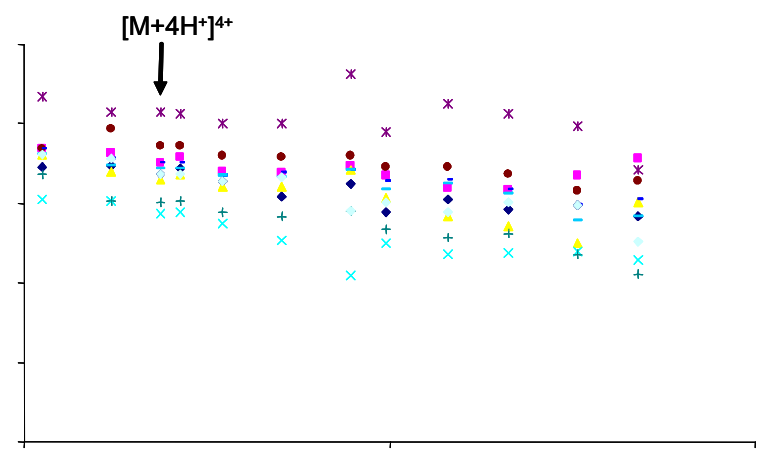

$\begin{array}{llllllllll}\mathrm{y}_{9} & \mathrm{y}_{10} & \mathrm{y}_{11} & \mathrm{y}_{12} & \mathrm{y}_{13} & \mathrm{y}_{14} \mathrm{y}_{15} & \mathrm{y}_{16} & \mathrm{y}_{17} & \mathrm{y}_{18} & \mathrm{y}_{19}\end{array}$
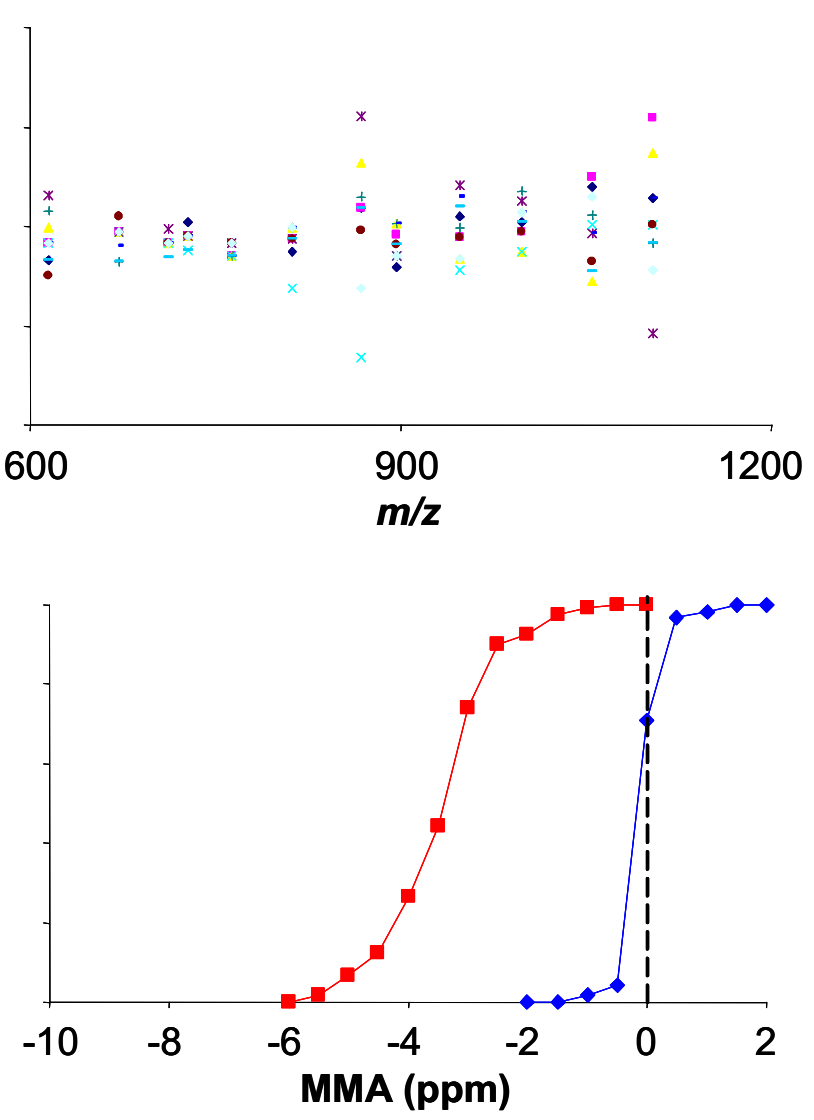

Figure 3. (a) Mass measurement accuracy as a function of $\mathrm{m} / \mathrm{z}$ for externally and (b) internally calibrated data. The different symbols reflect the ten different spectra analyzed. (c) Cumulative percentage plot of ions as a $\mathrm{m} / \mathrm{z}$ for the melittin data (red is externally calibrated data and blue is internally calibrated data).

and mass-selective dissociation of intact proteins while subsequently incorporating internal mass calibrants ions allowed for sub ppm MMA for melittin and low ppm MMA for ubiquitin. These data demonstrate that the dual electrospray source combined with tandem QFT-ICR MS data can reliably yield extremely high MMA when compared with other methods of calibration. Coupled with stronger magnetic fields [38], this method of internally calibrating top-down proteomic data has the potential to im- prove MMA even further. We are currently working on extending these findings to larger proteins, other methods of dissociation (e.g., electron capture dissociation [39] using alternative pulse sequences, optimizing internal mass calibrants, and data-dependent acquisition.

\section{Acknowledgments}

The authors thank Jennifer L. Frahm for designing the sequences of the iodopeptides. The authors gratefully acknowledge financial 

$M Q$ I F V K T L T G K T I T L E V ELPS D T I E $N \vee K A K I Q D K E G I L P D \mid Q Q R$ L I F A G K

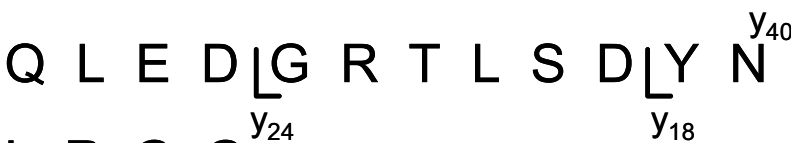 $L R G G^{y_{24}}$ $\mathrm{y}_{40} \quad \mathrm{y}_{37}$
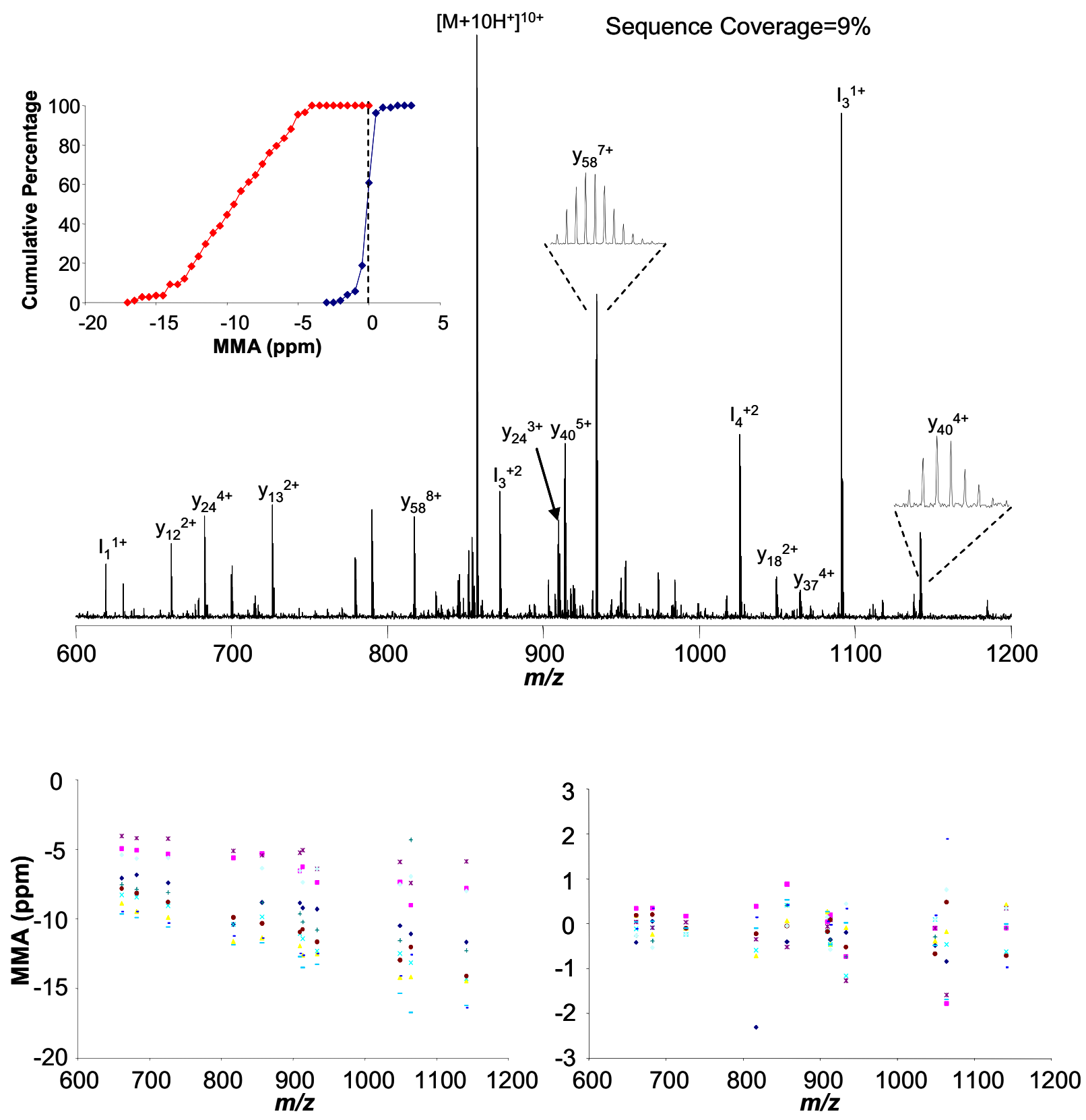

Figure 4. Ubiquitin primary sequence and denotation of observed y-ions. Dual ESI Q-FT-ICR tandem mass spectra of the $10+$ charge-state of ubiquitin using the four iodopeptides as internal standards. Plot of MMA as a function of $\mathrm{m} / \mathrm{z}$ for externally (bottom left) and internally calibrated data (bottom right). The cumulative percentage as a function of MMA is shown (middle left) for the externally calibrated data (red) and internally calibrated data (blue). 
support received from the National Cancer Institute, National Institutes of Health (R33 CA105295), The William R. Kenan, Jr. Fund for Engineering, Technology, and Science, the W. M. Keck Foundation, and North Carolina State University.

\section{References}

1. McIver, R. T.; Hunter, R. L.; Bowers, W. D. Coupling a Quadrupole Mass-Spectrometer and a Fourier-Transform Mass-Spectrometer. Int. J. Mass Spectrom. Ion Processes 1985, 64(1), 67-77.

2. Wang, Y.; Shi, S. D. H.; Hendrickson, C. L.; Marshall, A. G. MassSelective Ion Accumulation and Fragmentation in a Linear Octopole Ion Trap External to a Fourier Transform Ion Cyclotron Resonance Mass Spectrometer. Int. J. Mass Spectrom. 2000, 198(1/2), 113-120.

3. Harkewicz, R.; Belov, M. E.; Anderson, G. A.; Pasa-Tolic, L.; Masselon, C. D.; Prior, D. C.; Udseth, H. R.; Smith, R. D. ESI-FTICR Mass Spectrometry Employing Data-Dependent External Ion Selection and Accumulation. J. Am. Soc. Mass Spectrom. 2002, 13(2), 144-154.

4. Patrie, S. M.; Charlebois, J. P.; Whipple, D.; Kelleher, N. L.; Hendrickson, C. L.; Quinn, J. P.; Marshall, A. G.; Mukhopadhyay, B. Construction of a Hybrid Quadrupole/Fourier Transform Ion Cyclotron Resonance Mass Spectrometer for Versatile MS/MS Above $10 \mathrm{kDa}$. J. Am. Soc. Mass Spectrom. 2004, 15(7), 1099-1108.

5. Syka, J. E. P.; Marto, J. A.; Bai, D. L.; Horning, S.; Senko, M. W.; Schwartz, J. C.; Ueberheide, B.; Garcia, B. Busby, S. Muratore, T. Shabanowitz, J.; Hunt, D. F. Novel Linear Quadrupole Ion Trap/FT Mass Spectrometer: Performance Characterization and Use in the Comparative Analysis of Histone $\mathrm{H} 3$ Posttranslational Modifications. J. Proteome Res. 2004, 3(3), 621-626.

6. Loo, J. A.; Edmonds, C. G.; Smith, R. D. Primary Sequence Information from Intact Proteins by Electrospray Ionization Tandem Mass-Spectrometry. Science 1990, 248(4952), 201-204.

7. Kelleher, N. L.; Lin, H. Y.; Valaskovic, G. A.; Aaserud, D. J.; Fridriksson, E. K.; McLafferty, F. W. Top Down Versus Bottom Up Protein Characterization by Tandem High-Resolution Mass Spectrometry. J. Am. Chem. Soc. 1999, 121(4), 806-812.

8. Kelleher, N. L. Top-Down Proteomics. Anal. Chem. 2004, 76(11), 196A203A.

9. Reid, G. E.; McLuckey, S. A. “Top Down” Protein Characterization Via Tandem Mass Spectrometry. J. Mass Spectrom. 2002, 37(7), 663-675.

10. Bogdanov, B.; Smith, R. D. Proteomics by FTICR Mass Spectrometry: Top Down and Bottom Up. Mass Spectrom. Rev. 2005, 24(2), 168-200.

11. Jeffries, J. B.; Barlow, S. E.; Dunn, G. H. Theory of Space-Charge Shift of Ion-Cyclotron Resonance Frequencies. Int. J. Mass Spectrom. Ion Processes 1983, 54(1/2), 169-187.

12. Francl, T. J.; Sherman, M. G.; Hunter, R. L.; Locke, M. J.; Bowers, W. D.; McIver, R. T. Experimental Determination of the Effects of SpaceCharge on Ion-Cyclotron Resonance Frequencies. Int. J. Mass Spectrom. Ion Processes 1983, 54(1/2), 189-199.

13. Zhang, L. K.; Rempel, D.; Pramanik, B. N.; Gross, M. L. Accurate Mass Measurements by Fourier Transform Mass Spectrometry. Mass Spectrom. Rev. 2005, 24(2), 286-309.

14. Easterling, M. L.; Mize, T. H.; Amster, I. J. Routine Part-Per-Million Mass Accuracy for High-Mass Ions: Space-Charge Effects in MALDI FT-ICR. Anal. Chem. 1999, 71(3), 624-632.

15. Taylor, P. K.; Amster, I. J. Space Charge Effects on Mass Accuracy for Multiply Charged Ions in ESI-FTICR. Int. J. Mass Spectrom. 2003, 222(1/3), 351-361

16. Johnson, K. L.; Ovsyannikova, I. G.; Madden, B. J.; Poland, G. A.; Muddiman, D. C. Accurate Mass Precursor Ion Data and Tandem Mass Spectrometry Identify a Class I Human Leukocyte Antigen A*0201Presented Peptide Originating from vaccinia virus. J. Am. Soc. Mass Spectrom. 2005, 16(11), 1812-1817.

17. Masselon, C.; Tolmachev, A. V.; Anderson, G. A.; Harkewicz, R.; Smith, R. D. Mass Measurement Errors Caused by "Local" Frequency Perturbations in FTICR Mass Spectrometry. J. Am. Soc. Mass Spectrom. 2002, 13(1), 99-106.

18. Muddiman, D. C.; Oberg, A. L. Statistical Evaluation of Internal and External Mass Calibration Laws Utilized in Fourier Transform Ion Cyclotron Resonance Mass Spectrometry. Anal. Chem. 2005, 77(8), 2406-2414.

19. Bruce, J. E.; Anderson, G. A.; Brands, M. D.; Pasa-Tolic, L.; Smith, R. D. Obtaining More Accurate Fourier Transform Ion Cyclotron Resonance Mass Measurements Without Internal Standards Using Multiply Charged Ions. J. Am. Soc. Mass Spectrom. 2000, 11(5), 416-421.
20. Hannis, J. C.; Muddiman, D. C. A Dual Electrospray Ionization Source Combined with Hexapole Accumulation to Achieve High Mass Accuracy of Biopolymers in Fourier Transform Ion Cyclotron Resonance Mass Spectrometry. J. Am. Soc. Mass Spectrom. 2000, 11(10), 876-883.

21. Nepomuceno, A. I.; Muddiman, D. C.; Bergen, H. R.; Craighead, J. R. Burke, M. J.; Caskey, P. E.; Allan, J. A. Dual Electrospray Ionization Source for Confident Generation of Accurate Mass Tags Using Liquid Chromatography Fourier Transform Ion Cyclotron Resonance Mass Spectrometry. Anal. Chem. 2003, 75(14), 3411-3418.

22. Flora, J. W.; Hannis, J. C.; Muddiman, D. C. High-Mass Accuracy of Product Ions Produced by SORI-CID Using a Dual Electrospray Ionization Source Coupled with FTICR Mass Spectrometry. Anal. Chem. 2001, 73(6), 1247-1251.

23. Null, A. P.; Hannis, J. C.; Muddiman, D. C. Genotyping of Simple and Compound Short Tandem Repeat Loci Using Electrospray Ionization Fourier Transform Ion Cyclotron Resonance Mass Spectrometry. Anal. Chem. 2001, 73(18), 4514-4521.

24. Frahm, J. L.; Howard, B. E.; Heber, S.; Muddiman, D. C. Accessible Proteomics Space and Its Implications for Peak Capacity for Zero-, Oneand Two-Dimensional Separations Coupled with FT-ICR and TOF Mass Spectrometry. J. Mass Spectrom. 2006, 41(3), 281-288.

25. Chalmers, M. J.; Hakansson, K.; Johnson, R.; Smith, R.; Shen, J. W.; Emmett, M. R.; Marshall, A. G. Protein Kinase A Phosphorylation Characterized by Tandem Fourier Transform Ion Cyclotron Resonance Mass Spectrometry. Proteomics 2004, 4(4), 970-981.

26. Nepomuceno, A. I.; Mason, C. J.; Muddiman, D. C.; Bergen, H. R. Zeldenrust, S. R. Detection of Genetic Variants of Transthyretin by Liquid Chromatography-Dual Electrospray Ionization Fourier-Transform Ion-Cyclotron-Resonance Mass Spectrometry. Clin. Chem. 2004, 50(9), 1535-1543

27. Johnson, K. L.; Mason, C. J.; Muddiman, D. C.; Eckel, J. E. Analysis of the Low Molecular Weight Fraction of Serum by LC-Dual ESI-FT-ICR Mass Spectrometry: Precision of Retention Time, Mass, and Ion Abundance. Anal. Chem. 2004, 76(17), 5097-5103.

28. Lee, S. W.; Berger, S. J.; Martinovic, S.; Pasa-Tolic, L.; Anderson, G. A.; Shen, Y. F.; Zhao, R.; Smith, R. D. Direct Mass Spectrometric Analysis of Intact Proteins of the Yeast Large Ribosomal Subunit Using Capillary LC/FTICR. Natl. Acad. Sci. U.S.A. 2002, 99(9), 5942-5947.

29. Wolters, D. A.; Washburn, M. P.; Yates, J. R., III. An Automated Multidimensional Protein Identification Technology for Shotgun Proteomics. Anal. Chem. 2001, 73(23), 5683-90.

30. Patrie, S. M.; Ferguson, J. T.; Robinson, D. E.; Whipple, D.; Rother, M.; Metcalf, W. W.; Kelleher, N. L. Top Down Mass Spectrometry of $<60-\mathrm{kDa}$ Proteins from Methanosarcina acetivorans Using Quadrupole FTMS with Automated Octopole Collisionally Activated Dissociation. Mol. Cell. Proteomics. 2006, 5(1), 14-25.

31. Guan, S. H.; Marshall, A. G.; Wahl, M. C. MS/MS with High Detection Efficiency and Mass Resolving Power for Product Ions in FourierTransform Ion-Cyclotron Resonance Mass-Spectrometry. Anal. Chem. 1994, 66(8), 1363-1367.

32. Patrie, S. M.; Robinson, D. E.; Meng, F. Y.; Du, Y.; Kelleher, N. L. Strategies for Automating Top-Down Protein Analysis with Q-FTICR MS. Int. J. Mass Spectrom. 2004, 234(1/3), 175-184.

33. Roth, M. J.; Forbes, A. J.; Boyne, M. T.; Kim, Y. B.; Robinson, D. E. Kelleher, N. L. Precise and Parallel Characterization of Coding Polymorphisms, Alternative Splicing, and Modifications in Human Proteins by Mass Spectrometry. Mol. Cell. Proteomics 2005, 4(7), 1002-1008.

34. Fernandez, F. M.; Wysocki, V. H.; Futrell, J. H.; Laskin, J. Protein Identification Via Surface-Induced Dissociation in an FT-ICR Mass Spectrometer and a Patchwork Sequencing Approach. J. Am. Soc. Mass Spectrom. 2006, 17(5), 700-709.

35. Kaiser, N. K.; Anderson, G. A.; Bruce, J. E. Improved Mass Accuracy for Tandem Mass Spectrometry. J. Am. Soc. Mass Spectrom. 2005, 16(4), 463-470.

36. Thomas, C. E.; Kelleher, N. L.; Mizzen, C. A. Mass Spectrometric Characterization of Human Histone H3: A Bird's Eye View. J. Proteome Res. 2006, 5(2), 240-247.

37. Schwartz, B. L.; Bursey, M. M. Some Proline Substituent Effects in the Tandem Mass-Spectrum of Protonated Penta-alanine. Biol. Mass Spectrom. 1992, 21(2), 92-96.

38. Marshall, A. G.; Guan, S. H. Advantages of High Magnetic Field for Fourier Transform Ion Cyclotron Resonance Mass Spectrometry. Rapid Commun. Mass Spectrom. 1996, 10(14), 1819-1823.

39. Zubarev, R. A.; Kelleher, N. L.; McLafferty, F. W. Electron Capture Dissociation of Multiply Charged Protein Cations. A Nonergodic Process. J. Am. Chem. Soc. 1998, 120(13), 3265-3266. 